\title{
2.7. THE EVOLUTION OF E-RECRUITMENT: THE INTRODUCTION OF ONLINE RECRUITER
}

\begin{abstract}
Summary
The evolution of e-recruitment in the last 15 years has led to the emergence of new techniques of recruitment for the traditional recruiter. These techniques can change the function of a simple recruiter in an online recruiter. In this paper we have identified new tasks, skils and qualifications for the online recruiter function. "Recruitment is, in reality, job marketing" (Maurer and Liu, 2007), and this is the reason why online recruiter must constantly emphasize "the creation of a virtual recruiting environment" to attract talented employees which can provide long-term competitive advantage to organization. This virtual recruitment environment includes the company website that can be used in recruitment process, social networks and professional recruitment sites. Another online recruiter task is to create the opportunity and to motivate the colleagues in the organization, to participate in the recruitment process by posting and distributing available jobs in the virtual environment (social networks). The online recruiter must "cultivate a strong employment brand in online environment" (Ollington, Gibb and Harcourt, 2013). All these tasks require new skils and qualifications for recruiter.

The purpose of this paper is to create a job description for online recruiter. This job description suggests new tasks, skils and qualifications for traditional recruiter. It defines the scope of this new job, the duties and the responsibilities. The purpose of all these is the transformation of traditional recruiter in online recruiter.

The article ends with recommendations in terms of improving recruitment techniques and online practices.
\end{abstract}

Keywords: e-recruitment, job description, online recruiter

\section{Introduction}

E-recruitment is a subject often discussed in the specialized literature. In the mid of 1990s the Internet appears for the first time as a recruitment tool, giving rise to a phenomenon called in that time recruiting revolution (Boydell, 2002 quoted by Dhamija, 2012). Over the years, several synonymous terms describing the notion of erecruitment were identified: e-recruitment, web-based recruiting, online recruiting, web recruiting, recruiting online, recruiting on the internet, electronic resume, internet recruiting, etc. (Wolfswinkel, Furtmueller and Wilderom, 2010).

Recently at this list we can add other terms such as social media recruiting or social recruiting, which also falls under the scope of e-recruitment. More and more organizations are using their social media pages for recruitment purposes. Acikgoz 
(2013) presents a study conducted by Jobvite where „Ninety-two percent of organizations were using or planning to use social media for recruitment in 2012".

To the transformation of human resources recruitment function in e-recruitment, the evolution of technology information also contributed significantly by using information systems for the collection, storage, processing and the use of information in the field of human resources.

E-recruiting experienced a strong development in a short time. Given the current context, the evolution of technology has made its mark in recruitment due to the large number of companies looking for candidates using the Internet, but the large number of candidates applying to a job using online tools. Finding a talented candidate that fits the job has become more difficult. E-recruitment represents a solution for companies that are trying to find the ideal candidate to generate them competitive advantage, helping also the candidate.

Dhamija (2012) shows that "e-recruiting revolutionized the complete recruiting process" and the Internet is "acting as a link between employers and job seekers". These major changes in the recruitment filed, besides having greatly improved the work methods, they have created new work tasks for the recruiter.

Until now, many studies were focused on explaining the phenomenon of e-recruitment point of view of job seekers or employers. Over the years the studies regarding erecruitment were made from several angles of various management-oriented subdisciplines such as information systems, marketing, psychology, and human resources, giving the field of its interdisciplinary slant (Wolfswinkel, Furtmueller and Wilderom, 2010). Wolfswinkel et al (2010) realized a study of the specialized literature and selected 45 articles when they discovered three important perspectives. Most articles were conceived from the perspective of the applicant (19 items) then in terms of organization, several articles from different perspectives and only a recruiter perspective article. In this paper we will focus on the recruiter and its new tasks and responsibilities that appeared with the emergence and development of e-recruitment.

The ultimate goal is to propose a new job, moving from the traditional recruiter to online recruiter.

\section{E-recruiting evolution and design}

Recruitment function occupies an important role in the organization because companies are always looking to attract the most talented employees on a job that can them generate competitive advantage. As the psychologist and physician George Crane said "There is no future in any job. The future lies in the man who holds the job ". Deillon (2014) explain very simple that e-recruitment "is a new technological mean for selecting one of the companies' most crucial resources, i.e. human resource ".

Deillon (2014) quotes also Malinowski, Keim, \& Weitzel when he is describing the four different phases of e-recruitment evolution. They found two dimensions "degree of process integration" and "time" to determine the four phases (Figure 1).

Phase 1: The introduction of isolated solutions in the e-recruitment process for single activities such as the applicant data storage in computer systems. With the using of 
Internet appeared the possibility to post vacancies on the company's website or on the job portals, but also the possibility to search of a job and CV databases of these portals. Phase 2: In this phase appears the integrated applicant management system. This system wants to attract potential candidates, post vacancies, and receive applications from those who are looking for a job and even the final selection.

Phase 3: The information systems ensure compatibility of external service providers with company information systems providing a continuous flow in the recruitment process.

Phase 4: It involves a final solution that covers the entire recruitment process, integrating computer systems but also web-based tools that allow data transfer between the company and other external parties.

Figure 1: The Recruitment Phase Model

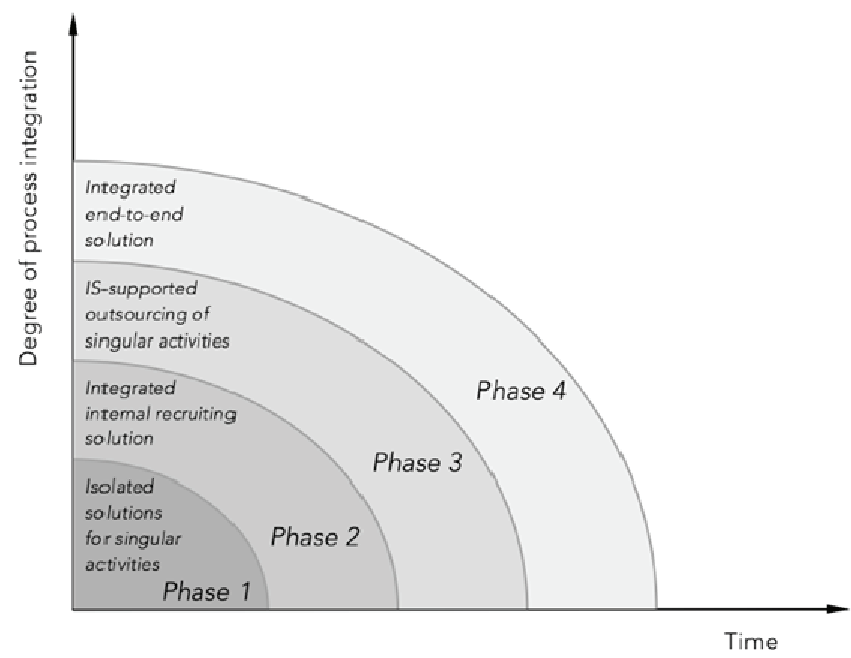

Source: Malinowski, Keim, \& Weitzel, 2005 quoted by Deillon Céline, 2014

These four phases are not generally available, but offers an itinerary and organizations tend to follow this model in integrating new techniques and methods of recruitment. Follow these four phases can highlight also the e-recruitment progress, from the simply use of a PC (from 1980s) for data storage, to the use of Internet and tools that rely on web for attracting, selecting and hiring the suited candidates.

Wolfswinkel et al. (2010) identifies three important directions of e-recruitment: "adding recruiting pages to an existing organization site, using websites specialized in recruiting, and using electronic advertisements on media sites". They define erecruiting as "the online attraction and identification of potential employees using corporate or commercial recruiting websites, electronic advertisements on other websites, or an arbitrary combination of these channels including optional methods such as remote interviews and assessments, smart online search agents or interactive communication tools between recruiter and applicant.

For several years, the phenomenon of social networks stands out in the recruitment process. Ollington Nickolas et al. (2013) bring us into account several studies showing 
that recruiters and companies are increasingly using online social networking to attract and screen candidates as part of the hiring process. They present a study realized by Careerbuilder.com in which $45 \%$ of companies use social recruiting. Another more recent study made by Jobvite.com (2014) shows that employers plan to increase their investment in a range of recruiting methods and on top (73\%) of these methods, social networks can be found. This study of Jobvite.com also shows which social sites are preferred by recruiters: Linkedin is on top with 94\%, then Facebook with 66\%, Twitter with $52 \%$ and the list goes with Google plus $21 \%$, etc. Although these social networks were not specifically designed for recruiting, they became tools for recruitment. For example Linkedin was not designed specifically for the recruitment industry, but it has become the preferred tool of recruitment of more recruiters and companies (Vick and Walsh, 2008).

These changes in the recruitment procedure lead to the need to manage some specific challenges for the recruiter. Once identified these challenges transform the traditional recruiter in an online recruiter who owns new skills, tasks and responsibilities.

\section{The online recruiter - Job Description}

With the advent of recruitment has been much talk about reducing costs and time spent in the recruiting stage. As e-recruitment has evolved, a transfer from the traditional recruitment to e-recruitment took place. This new way to attract candidates for a job also brought with it new tasks and responsibilities that change the traditional recruiter's activity. These tasks and responsibilities require a new set of skills and qualifications that can create a new profession: "online recruiter".

Companies need an online recruiter to adapt the recruitment process to the information age with the aim of "cultivated a strong employment brand in the online environment" (Ollington, Gibb and Harcourt, 2013). Another purpose for which we need the online recruiter is to attract applicants by building an online social network (Ollington, Gibb, Harcourt, 2013). Another online recruiter task is to create the opportunity and to motivate the colleagues in the organization, to participate in the recruitment process by posting and distributing available jobs in the virtual environment (social networks).

Maurer and Liu (2007) say that "recruitment is, in reality, job marketing" and this is the reason why online recruiter must constantly emphasize "the creation of a virtual recruiting environment" to attract talented employees which can provide long-term competitive advantage to organization. This virtual recruitment environment includes the company website that can be used in recruitment process, social networks and professional recruitment sites.

Some tasks and responsibilities are similar to those of traditional recruiter. Table 1 shows the traditional recruiter's job description.

We took a traditional recruiter job description from a company with over 1,600 employees in Romania and we modified it only to highlight the duties and responsibilities of an online recruiter (Table2.) The way these tasks are executed and finalized change the traditional recruiter's work, in fact all the developments of erecruitment based on "Internet, has completely changed the role of the traditional recruiter" (Dhamija, 2012). 
Table 1: Traditional Job Description

\begin{tabular}{|c|c|}
\hline JOB DESCRIPTION & G ANALYST / INTEGRATION EMPLOYEES \\
\hline Internal function & HR SPECIALIST \\
\hline DEPARTEMENT & Human resources \\
\hline STUDIES & specialized higher education \\
\hline hierarchical relations & $\begin{array}{l}\text { hierarchically subordinate to the head of } \\
\text { department }\end{array}$ \\
\hline DUTIES, RESPONSIBILITIES & \\
\hline 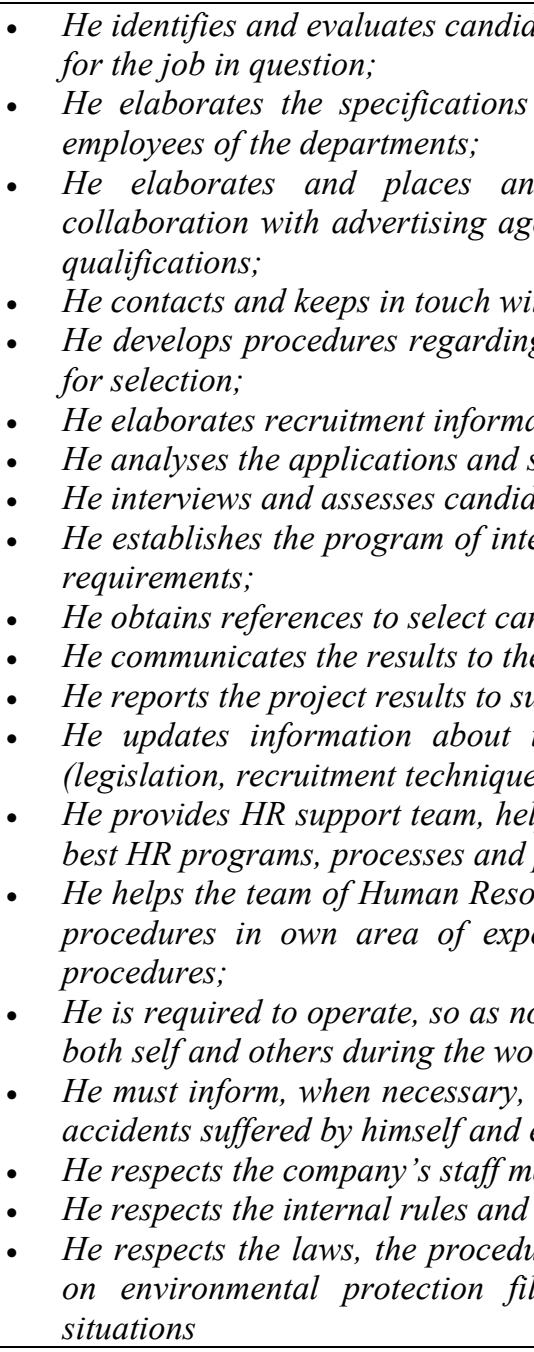 & $\begin{array}{l}\text { es for available jobs and proposes the most suitable } \\
\text { f the available job in discussion with officers or } \\
\text { uncements in newspapers and magazines (in } \\
\text { cy) in order to attract candidates with appropriate } \\
\text { the recruitment agency; } \\
\text { the selection of candidates and goes at universities } \\
\text { ve materials specific to the organization; } \\
\text { ects the appropriate ones; } \\
\text { es by applying psychological tests and knowledge; } \\
\text { views and informs he candidate about the future job } \\
\text { idates; } \\
\text { ejects candidates; } \\
\text { eriors, getting feedback from internal client; } \\
\text { e legislation and informs the other departments } \\
\text { procedures) } \\
\text { ing to analyse the employees requests to provide the } \\
\text { ocedures; } \\
\text { ces to implement and develop programs, processes, } \\
\text { tise, in accordance with company processes and } \\
\text { to expose to danger, injury or occupational disease, } \\
\text {; supervisor and / or employer, about occupational } \\
\text { vironmental accidents; } \\
\text { ork procedures; } \\
\text { l, security and occupational health, emergency } \\
\text { os indications; }\end{array}$ \\
\hline Name and surname of the employee & Complied by \\
\hline Signature & \\
\hline Date: 16.04 .2015 & Date: 16.04 .2015 \\
\hline
\end{tabular}

Source: a company with over 1,600 employees in Romania 
Table 2: Online recrutier - Job Description

\begin{tabular}{|l|c|}
\hline JOB DESCRIPTION & Online Recrutier / INTEGRATION EMPLOYEES \\
\hline Internal function & HR SPECIALIST \\
\hline DEPARTEMENT & Human resources \\
\hline STUDIES & specialized higher education \\
\hline Hierarchical relations & hierarchically subordinate to the head of department \\
\hline DUTIES, RESPONSIBILITIES & \\
\hline
\end{tabular}

- He identifies and evaluates candidates for available jobs and proposes the most suitable for the job in question;

- He elaborates the specifications of the available job in discussion with officers or employees of the departments;

- He elaborates and place online ads to attract candidates with appropriate qualifications for the job;

- He contacts and liaises with other external recruitment factors such as specialized recruiting sites social sites;

- He elaborates online procedures and motivates colleagues to participate in the recruitment process by distributing job offers and cultivating an employer brand on the social networks.

- He creates a virtual environment by building and maintaining an online social network structure;

- He adapts recruitment informative materials specific to the organization using the online environment;

- He manages the company's career page or website and also the social media pages.

- He deals with management database and analyses the applications by choosing the appropiate ones.

- He obtains references about the selected candidates;

- He reports the projects results to superiors, getting feedback from internal client;

- He updates information about the legislation and informs the other departments (legislation, recruitment techniques, procedures;

- He provides HR support team, helping to analyse the employees requests to provide the best HR programs, processes and procedures;

- He helps the team of Human Resources to implement and develop programs, processes, procedures in own area of expertise, in accordance with company processes and procedures;

- He is required to operate, so as not to expose to danger, injury or occupational disease, both self and others during the work;

- He must inform, when necessary, his supervisor and / or employer, about occupational accidents suffered by himself and environmental accidents;

- He respects the company's staff management indications;

- He respects the internal rules and work procedures;

- He respects the laws, the procedures in the area of responsibility and company policy on environmental protection filed, security and occupational health, emergency situations

\begin{tabular}{|l|l|} 
Name and surname of the employee & Complied by \\
\cline { 1 - 1 } Signature & Date: \\
\hline Date: &
\end{tabular}


Another online recruiter's task is to create the opportunity to motivate and the colleagues in the organization, to participate in the recruitment process by posting and distributing available jobs in the virtual environment (social networks).

\section{Recommendations for improving online recruitment techniques and practices}

Regarding the techniques and methods used in online recruitment, it should be noted that there is no formula for success, they have to be adapted and specifically selected for each recruitment action. All these techniques and methods show both advantages and disadvantages, the online recruiter's role is to select the much more suited methods depending on job and the company he represents.

For example the advantages of an organization career sites are: candidate relationship management, high interest in jobs by job applicants and integration with existing systems. The disadvantages are the needs for IT specialists and high up front development cost (Lee, 2007). The situation of these disadvantages could be changed by creating an online job recruiter that must have the necessary IT skills to maintain the career site, and thus the company will not need an IT specialist for maintenance.

A future research direction would be to measure the level of satisfaction of the online recruiter and applicant, as a result of experiences during the various stages of online recruitment process. An analysis about e-satisfaction can be influenced by the websites and online service quality (Constantin, 2012). This analyse can differentiate in an emerging economy the online recruitment tools that promise lower margins and no higher profits. (Boşcai, 2015).

Figure 2 below shows the results from an exploratory study of an online recruitment company (job board) that illustrate consumer evaluations (Liljander, 2002).

Figure 2: Service elements of a job board and customer's cognitive and affective reactions

$$
\text { E-service offering - a job board }
$$

Customer evaluation

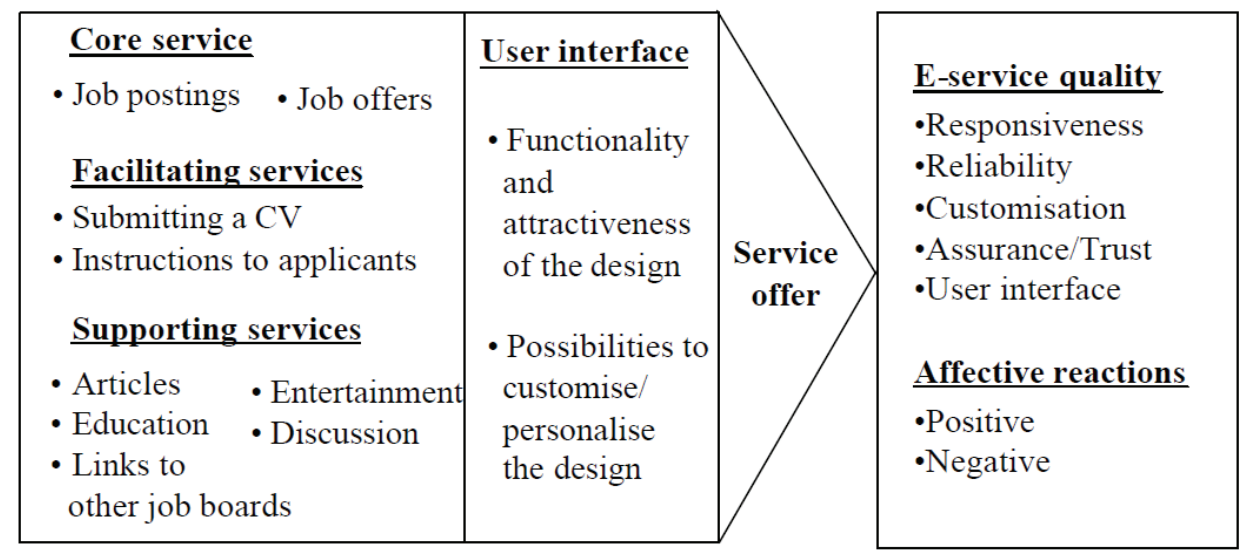

Source: Liljander, van Riel and Allard (2002) 
The above guidance can be used to study the changes that take place when the traditional recruitment process turns into online recruitment, the study of these changes can lead to the improvement of online recruitment tools. The figure below illustrates four elements offered by an online recruitment tool, with examples of procedures. Then it suggests five dimensions about the quality of services that an online recruitment tool provides.

These approaches indicate the necessity of continuous research and improvement of factors to attract future applicants but also to meet the needs of the organization by attracting those candidates that can generate value to the company (Constantin, 2012).

"A recent trend is for employers and recruiters to utilize social networking sites to screen candidates as part of the hiring process" (Vicknair et al., 2010). In this article, Vicknair et al. propose additional studies conducted from the perspective of the employer/ recruiter's attitude to answer questions about how often these tools are used and what would be the industries that use them. In this way the online recruiter can choose when it is relevant to use tools provided by social recruiting and when is not the case.

Vicknair et al. quotes Jacobs (2009) which defines the term social recruiting as "harnessing Web 2.0 technology developments and social media tools to communicate, employ, inform, and recruit our future talent,,The use of such social networking websites allows recruiters to connect to a broad array of talented and capable candidates in niche communities" (Vicknair et al., 2009). A disadvantage of these social networking websites is that applicants usually controls what they post and they would not post something that the employers would not like to see.

Future candidates must be prepared "for the new era of social recruitment" (Faliagka et al., 2012), they must have a profile on LinkedIn which they must update and invest time to have an extensive list of contacts, also the participation in online discussion in communities or blogs can give them greater visibility and thus can increase job offers. Parry and Tyson (2008) after an analysis of the use and success of online recruitment identify some steps that employers must take in order to improve their success in using online recruitment methods. They identified four such steps: (1) driving traffic to a corporate website, (2) use of back-office functionality, (3) creation of a talent pool and (4) branding and the provision of information to candidates.

- Driving traffic to a corporate website. If a company does not have a strong employment brand in the online environment and is not well known then it is very difficult to bring job seekers to their website. Such companies must adopte other "advertising channels such as jobs boards or print media to drive people to the site" and ,jobs boards were used to drive traffic to a company's corporate website through the use of a web link" (Parry and Tyson, 2008)

- Use of back-office functionality. Technological developments have created the opportunity to reduce the number of initial screening activities by using IT systems ("use of the back-office system") that automate certain functions for managing the recruitment process and reduce costs significantly.

- Creation of a talent pool. Applicant's data can be automatically recorded on a system without manual input. Data storage of some talented candidates within the organization and subsequent search in this database when a new vacancy appears, 
can bring several benefits to recruitment process such as reducing initial costs and reducing the time spent with screening activity.

- Branding and the provision of information to candidates. Candidates can learn more about the company and the future job through career information on the website, information that can be read, viewed through videos or listened to audio files. In this way, future candidates can do a better selection. These online recruitment technologies can easily be used to promote employer brand.

\section{Conclusions}

The Internet and the development of e-recruitment functions have changed the way the traditional recruiter perform his duties and responsibilities. These changes have led to the shaping of new jobs as "online recruiter," which besides the fact that he has new tasks and responsibilities, he must possess certain qualifications that traditional recruiter does not have. These qualifications might be for database management, skills and web designer abilities, qualifications and skills to use and select the appropriate softwear in order to solve specific recruitment problems, etc.

It is necessary to built analytical methods for online recruitment tools, so that online recruiter can choose the tools that attract the most talented people with minimal resources.

Online recruitment methods can be improved by increasing the corporate career site traffic, by using a back-office system, creating a talent pool and an employer branding with a lot of specific information available to future job candidates.

\section{Acknowledgement}

This work was supported from the European Social Fund through Sectorial Operational Programme Human Resources Development 2007-2013, project number POSDRU/159/1.5/S/134197 , project title "Performance and Excellence in Postdoctoral Research in Romanian Economics Science Domain"

\section{References}

1. Boşcai G. B. (2015): Niche Websites and online tools used in recruitment, SEA - Practical Application of Science, Volume III, Issue 1 (7) pp. 113-120., http://www.sea.bxb.ro/Article/SEA 7 18.pdf

2. Constantin, A-M. (2012): The antecedents of e-satisfaction and e-loyalty and the relationship between them, Timisoara Journal of Economics, eISSN: 1844-7139, volume 5, Issue 18, p. 236- 252, http://www.tje.uvt.ro/index.php/tje/article/view /163/ pdf.

3. Deillon, C. (2014): The advantages and challenges of turning towards e-recruitment for small and medium sized businesses (SME). Thesis avaible at https://diuf.unifr.ch/main/is/sites/diuf.unifr.ch.main.is/files/documents/student-project $\quad$ s/S2014_Celine_Deillon_0.pdf

4. Dhamija, P. (2012): E-recruitment: a road map towards E-human Resource Management, Researchers World: Journal of Arts, Science and Commerce Vol. 3, Issue: 3(2), pp. 33-39. 
5. Faliagka, E., Tsakalidis, A., Tzimas, G. (2012): An integrated e-recruitment system for automated personality mining and applicant ranking, Internet Research, Vol. 22 Iss: 5 pp. 551568, http://dx.doi.org/10.1108/10662241211271545

6. http://www.goodreads.com/quotes/140173-there-is-no-future-in-any-job-the-future-lies

7. https://www.jobvite.com/wp-content/uploads/2014/10/Jobvite_SocialRecruiting_Survey 2014.pdf

8. Lee In (2007): An Architecture for a next - Generation Holistic E-recruiting System, Comunications of the ACM, July 2007/Vol.50, No. 7.

9. Liljander, V.; van Riel C.R.; Allard, P. M. (2002): Customer satisfaction with e-services: The case of an online recruitment portal, Electronic services, http://citeseerx.ist.psu.edu/viewdoc/download?doi=10.1.1.199.2974\&rep=rep1\&type=pdf

10. Malinowski, J.; Keim, T.; Weitzel, T. (2005): Analyzing the Impact of IS Support on Recruitment Processes: An E-Recruitment Phase Model, AIS Electronic Library (AISeL), PACIS 2005 Proceedings Paper 81, http://aisel.aisnet.org/pa cis20 05/81

11. Maurer, D. S.; Liu, Y. (2007): Developing effective e-recruiting websites: Insights for managers from marketers, Business Horizons (2007) 50, 305-314. Available at: http://www.yupingliu.com/files/papers/maurer_liu_recruiting.pdf

12. Ollington, N.; Gibb, J.; Harcourt, M. (2013): Online social networks: an emergent recruiter tool for attracting and screening, Personnel Review, Vol. 42 No. 3, 2013, pp. 248-265, Emerald Group Publishing Limited, 0048-3486, DOI 10.1108/00483481311320390

13. Parry, E.; Tyson, S. (2008): An analysis of the use and success of online recruitment methods in the UK, Human Resource Management Journal, Vol. 18, Iss. 3, Pages 257-274, https://dspace.lib.cranfield.ac.uk/bitstream/1826/4228/1/Ana nalysis_of the use and success_of \%20online recruitment methods in the UK.pdf

14. Vick, B.; Walsh, D. (2008): Happy about LinkedIn for recruiting, available at: www.happyabout.info/linkedin4recruiting.php.

15. Vicknair, J.; Elkersh, D.; Yancey, K.; Budden, C. M. (2010): The use of social networking websites as a recruiting tool for employers, American Journal of Business Education, Volume 3, Number 117, http://dx.doi.org/10.19030/ajbe.v3i11.57

16. Wolfswinkel, J.; Furtmueller, E.; Wilderom, C. (2010): Reflecting on e-recruiting research using grounded theory, 18th European Conference on Information Systems, ECIS20100477.R1.

17. Acikgoz, Y. (2013): Social Media and Employee Recruitment: Too Much Pain For Not Much Gain, Thesis, Cranfield University 